\title{
Investigating ESL Adult Lexical Development with The Use of an Assistive Technology
}

\author{
Ewa Wasniewski, Patricia Boechler \\ University of Alberta, Canada
}

\begin{abstract}
The application of Assistive Technologies (AT) to support college students' English Language development is a developing area of research. This investigation uses qualitative research to investigate the experiences of a small sample of ESL adult learners using a specific AT to assist with an English course, at a Western Canadian college. By teaching and supporting the Read and Write Gold (R\&WG) program, ESL adult students demonstrate an overall benefit from learning the technology. Technological supports need to be researched further too continually grow and develop programs to meet the current needs of students and employers alike. The objective of this research was to determine if the use of AT increases ESL students' self reported vocabulary acquisition.
\end{abstract}

\section{Introduction}

Post-Secondary institutions, specifically Colleges, are being challenged to teach complex content areas while some students are still being enrolled with limited basic literacy skills. The issue has been magnified by the increase in English as a Second Language Learners (ESL) enrollment. Research indicates that some students may not have been taught sufficient basic skills necessary for fluent reading and deep processing [19]. Many Colleges are now requiring ESL students to take an entrance exam prior to admission into a career program. Frequently, the standardized Canadian Language Benchmark test is used to identify if students meet the requirements for enrollment. The exam has eight different levels which assess for language acquisition in the areas of; reading, reading comprehension, writing, and speaking [4]. Many college programs require the highest level (eight) on the CLB exam prior to entering a career program. Although many ESL students demonstrate the literacy capabilities and conversational fluency necessary for admission, anecdotal evidence has indicated that this group struggles with reading comprehension when faced with academic and technical text requirements [19]. As a result, ESL students are readily identified as a group that is academically at risk. Academic fluency is difficult to achieve and takes time with supports for a student to be able to transfer their knowledge [2]. Educational technologies have been used to train students on devices to support individual support and achievement. Due to students' limited technological awareness, many institutions are now providing computer writing or computer learning programs [17].

There is limited research regarding the application of Assistive Technologies (ATs) to assist in the development of ESL language skills. However, there is research in the area of ComputerAssisted Language Learning (CALL) which is defined as a computer application that can improve language acquisition through individual practice activities [10]. The focus and purpose of many CALL programs is rote memory and the identification of words to build vocabulary. This provides students the opportunity to practice, but does not teach them how to transfer their language knowledge to other content areas [10]. ATs provide different features that can be customized to the students' individual needs. By providing a computer program that has built in modification, the individual needs of more students can be met. The program that has been used in this research is called 'Read and Write Gold.' This program has many different features that support reading, writing, and researching on most computer programs and internet sites [24]. One of the key features that has been proven useful for struggling readers is the use of a text-to-speech feature [7]. This function reads the words aloud to the reader while highlighting the words that it is reading. "One type of technology development to overcome these students' reading problems are computer programs that provide synthetic speech output, synchronized with text (Kelemes, Epstein, Zuker, Grinber, \& Ilovitch, 2006) such as text to speech software," [14](p. 22). This research will identify which features in the R\&WG program are most used by a small sample of adult ESL learners, as well as report learners' feedback regarding which features supported individual vocabulary development.

\section{Literature Review}

The notion that technology can be used to enhance performance challenges traditional views held by those who claim that performance of tasks without the use of technology is superior to performance, which incorporates technology [7]. However, as classrooms become more diverse and educators are encouraged to teach in different modes, it is important to be aware of individual student needs and what technologies may be accessible to 
support their individual development. This becomes more critical in post-secondary programs where adult students enter the formal educational environment with limited prior education and, sometimes, poor English language skills. For students who struggle to master literacy skills Edyburn states, "We seek to capture the potential of technology for supporting the performance of struggling readers, such bias must be overcome in the quest to provide struggling students with appropriate tools to enhance their performance, learning, and achievement," [7](p. 151).

Technology is a way to even the playing field so all students have access to supportive learning. Specifically, for students working towards English language acquisition or mastery in a content area, technologies could support struggling readers in a positive way.

\subsection{Technology and Post Secondary}

A comprehensive review of American literacy courses identified effective practices in basic skills/development in college programs. Boroch, Fillpot, Hope, and Johnstone [1], first defined basic skills as, "the foundational skills in reading, writing, mathematics, learning skills, study skills, and English as a Second Language which are necessary for students to succeed in college-level work," (p. 82). When applying the idea of supporting and scaffolding basic skill development at the college level, different categories emerge. First, organizational, and administrative practices dictate through policies which skills are most important and what achievement level the students must obtain. The programming of the college specifically identifies the number of specialized services to which students have access. Next, staff development is mandated through the college, thus, all possible opportunities for professional growth needs to follow a theme. Finally, instructional practices explore effective andragogy techniques and technologies to support the development of basic skills in the classroom [1]. All of these categories are being addressed at many colleges but research has indicated that current practices are not reflecting current diverse students' needs.

Wald, Draffan and Seale [25] have discovered that university students may claim to be highly knowledgeable about technologies and be flexible in their intended use but this only applies to the programs that they use daily. They are uncomfortable with learning different programs or software due to lack of prior transferable knowledge. If post-secondary institutions wish to increase their course material delivery online, web designers need to create accessible web pages for assistive technologies [13]. One of the key issues mentioned in this study by the participants was the amount of time it took to learn new computer programs utilized by the university [25]. This extra expectation increases student frustration as they are trying to learn new programs in order to access on-line courses. Students with disabilities face more struggles in accessing course materials while trying to apply accessibility adoptions [25]. Part of this problem can be attributed to the assumption that students in post secondary have gained the necessary academic independence to transfer skills to different environments [25].

Lacina [14] conducted a literature review that distinguished different software that promotes language acquisition. The main purpose of the articles included in the review was to provide possible technologies that can meet students' diverse needs and enhance learning. The key for Lacina [14] was the attitudinal beliefs that need to be addressed that reflect the fear teachers have about using technologies in the classroom. This stems from personal inexperience and lack of training with software that has an impact on ESL student language acquisition. Lanina [14] interviewed two ESL language teachers about their beliefs and ideas surrounding the impact of technologies on their classroom. Two emerging themes were identified; first, how can technologies compensate for differences in the background of students while sustaining an engaged learning environment, and second, how can technologies provide students with the ability to control their own level of learning by providing choice and extra noninvasive support during class time.

Research has identified that individuals who play with different modes of technology over time will experience less frustration with newly introduced technology [11]. Playing games and social networking creates a technology schema that learners can build on as they encounter new technology.

\subsection{Assistive Technology}

To date, there has been little research regarding the use of AT to support language acquisition of adult ESL and Language Learners (LL). AT has been researched and applied within the field of Special Education to support students with disabilities. AT has been used to facilitate effective functioning in a wide variety of educational environments and contexts. It is used across age, ability and grade levels. This literature review will focus on the use of AT to facilitate vocabulary development and reading supports.

Research has noted, not just in special education but also in reading and language programs, the importance of teaching basic language skills [6]. When students become adults and are still struggling with reading, it suggests that they have not received the individualized support needed to scaffold their learning in the early phases [6]. AT has been 
incorporated into college curriculum to address reading weaknesses that developed earlier on in a student's educational experience [9]. For example, Engstrom [9] conducted two case studies that examined the benefits of AT for self-identified American students with disabilities registered in a reading and writing development class. The purpose of using AT in this study was to provide students quick access to strategic support of required tools [9]. The most prevalent concern noted in this study was the amount of time that was required to learn the device on top of regular class assignments [9]. It is imperative when supporting language development for adults with special needs, that the AT is purposefully matched for the strategic support of individual needs. Students with learning disabilities have often struggled throughout their educational careers; therefore, when students have an opportunity to learn new strategies, individualized support that facilitates intrinsic motivation is necessary to support their literacy development [21]. As these students are introduced to ATs, finding ways to help them incorporate the technology into their study habits will provide individualized support for meaningful learning [16].

Sorrell, Bell and McCallum [22] conducted a quantitative comparison of reading rate and comprehension between traditional teaching supports and the use of ATs. Their results showed that for strong readers, ATs reduced their reading and comprehension rates, while the use of ATs increased both comprehension and reading rate for weaker readers [22]. AT provides a link for struggling students by minimizing frustrations and providing constant feedback, thus increasing success [22]. This observation held true for a similar study conducted on struggling readers at a secondary school in Ireland [15]. Students were placed in one of three groups; a control group of computer users, Microsoft accessibility users that had access to Word and Word features and the AT users that were taught Word as well as Kurzweil 3000 [15]. AT, in particular textto-speech and homophonic spelling tools, improved test results for struggling readers compared to the Microsoft group and control group [15]. All of these tools provide several advantages to students with reading difficulties such as; direct support, success, and increased motivation [15]. In turn, this supports independence by providing individualized engaged learning opportunities for students.

In another study, Elkind and Elkind [8] identified text-to-speech software (TTS) that provided reading assistance for poor readers. In their research, poor readers and good readers were compared on the Wechsler Adult Intelligence Scale (WAIS) Vocabulary test [8]. Poor readers were defined as students that may have a learning disability or attention disorder. Often these students have similar struggles because they have problems with: "reading slowly, rereading passages, struggle to decode unfamiliar words, and interrupt their reading frequently to recover from fatigue and stress. Reading takes them much more time than it does their peers," [8] (p. 11). Research has indicated that students who read below their grade level are unable to understand important concepts, and do not acquire the necessary knowledge to progress with their peers [19]. As students move into the next grade level, texts that are more complex require a higher application of sophisticated strategies; therefore, students who are not engaged miss opportunities to become proficient in comprehending complex texts [19].

Phayer [18] researched the benefits of TTS AT for college students with dyslexia. A case study of 22 self-identified dyslexic students reported that motivation was a key struggle that they faced within the College setting. They were provided 4-6 weeks of training on the R\&WG program [18]. Over the training sessions, students were taught and supported in using the different functions available on the R\&WG program [18]. The results indicated that the R\&WG program was useful to support the individual needs of the students involved in the study. Specifically, the 'play/pause/forward/rewind/stop buttons' were extremely useful for $15 \%$ of students and $54 \%$ of students found the 'text reader facility' very useful [18]. "Synthesized speech reading of text by the computer allows users to access information aurally as well as, or instead of, reading it on the screen or in a paper version," [5] (p. 1-2). Due to the similarities with ESL and struggling readers, educational technologies such as TTS may create the authentic, supportive activity that teachers strive to provide.

The use of ATs for reading support indicates that different features can effectively support the development of reading rate and comprehension of students with disabilities as well as struggling students. Specifically, the TTS feature provides students control in hearing literature that they are reading, which enables them to better understand the content. Besides reading rate and comprehension issues, research suggests one of the key struggles in literacy development for some students are phonological decoding deficits that may result in word identification challenges and vocabulary development [23]. This is magnified for students who are learning a second language because they are trying to understand individual words at the same time as they are trying to understand the words in the context of a sentence. Studies have shown that students with weak comprehension have deficits in receptive vocabulary, semantic processing, grammatical understanding, and spoken discourse [3]. Research has provided insight on how to support struggling students to increase their success and desire to continue schooling. 


\section{Procedure}

Participants for this study were in their first semester of taking the Practical Nurse Diploma for Internationally Educated Nurses (PNDIEN) at a community college. One of the first classes that they were required to take is an English class that focuses on being able to find, read, and analyze health related topic using medical journals. Students are then taught the writing process and compose a 12-page essay. The critical and analytical reading, thinking, and writing skills taught in this course assist in the completion of other courses, which follow. Often students in this program do not have prior experience in analytical reading, thinking, and writing in English. They also have not had the opportunity to read and analyze Canadian medical research documents. The researcher has identified these skills as learning obstacles, which can lead to a frustrations and decreasing success. All participants in this course were adults and have prior knowledge in the area of nursing or health care. Furthermore, all of the students were in a full time program taking three other classes at the same time. The English course was offered twice a week in 80-minute blocks.

Data was collected from four self-identified ESL adults registered in the English course at a Western Canadian College. The participants moved to Canada from their respective countries within the last five years and had achieved a level 8 on the CLB entrance exam. The purpose of this study was to first identify prior computer experience and then to determine if participants found the application of R\&WG feature beneficial to their vocabulary development as they read medical research articles. Some of the articles were included as course content and other articles were researched by the participants and included in their essay.

In addition to their regular class time, the researcher provided six one-hour group sessions, which ran throughout the fall semester. The sessions progressed through various activities to teach participants how to first use the College's computer system, access the R\&WG program, and how to access different features in the R\&WG program. Data was collected using three questionnaires. The first questionnaire, Computer Experience Questionnaire, collected data to identify prior computer knowledge, social, programming, and educational computer use at the start of the research study. The second questionnaire was the AT Post Vocabulary Questionnaire, it was collected at the end of the study and comprised of open and closed questions to identify features used by participants from the R\&WG program. The third questionnaire was an over all experience questionnaire about the program sessions offered by the research as well as participant reflections.

\section{Results}

All of the experiences reported by the participants are reported in this section with associated analysis. Due to the small sample, size participants were coded and all information pertaining to each individual participant is presented.

\subsection{Descriptive Statistics}

The Computer Experience Questionnaire (CEQ) collects information in three areas pertaining to individual computer background. First, participants are asked to identify how often they have used video gaming or social networking programs. Next, a list of twenty current software titles, which are accessible to the general public as well as at the college, was used to identify how much software they recognized. Finally, the last section has a list of thirteen different educational activities that often required of adult students in a post-secondary environment. Participants were asked to identify which activities they have engaged in prior to the start of this research study.

Table 1. CEQ by Each Individual Participant

\begin{tabular}{|c|c|c|c|c|}
\hline Participants & \multicolumn{4}{|c|}{ Computer Experience Questionnaire (CEQ) } \\
\hline & $\begin{array}{l}\text { Average amount of } \\
\text { hours using Video } \\
\text { Games and Social } \\
\text { Online Programs }\end{array}$ & $\begin{array}{c}\text { List of Software } \\
\text { Titles }\end{array}$ & $\begin{array}{c}\text { Prior } \\
\text { Education } \\
\text { Activities }\end{array}$ & $\begin{array}{c}\text { Educational } \\
\text { Activity Programs }\end{array}$ \\
\hline Female 1 & Not at all & $\begin{array}{l}\text { Microsoft Word, } \\
\text { Excel, Adobe } \\
\text { Acrobat }\end{array}$ & $23 \%$ & $\begin{array}{l}\text { Library Data Base, } \\
\text { Online Journals, } \\
\text { Digital books. }\end{array}$ \\
\hline Female 2 & Not at all & Microsoft Word & $30 \%$ & $\begin{array}{c}\text { Library Data Base, } \\
\text { Online Journals, } \\
\text { HTML,WebCT. }\end{array}$ \\
\hline
\end{tabular}




\begin{tabular}{|c|c|c|c|c|}
\hline Male 1 & 1-3 hours & $\begin{array}{l}\text { Microsoft Word, } \\
\text { Power Point, } \\
\text { Skype }\end{array}$ & $30 \%$ & $\begin{array}{c}\text { Slide } \\
\text { Presentation, } \\
\text { Library Data Base, } \\
\text { Online Journals, } \\
\text { WebCT. }\end{array}$ \\
\hline Male 2 & Not at all & $\begin{array}{l}\text { Microsoft Word } \\
\text { and Power Point }\end{array}$ & $23 \%$ & $\begin{array}{c}\text { Slide } \\
\text { Presentation, } \\
\text { Library Data Base, } \\
\text { Online Journals. }\end{array}$ \\
\hline
\end{tabular}

Specifically, participant female one identified on the CEQ that she has not engaged in video gaming or social networking. This indicates that she does not use the computer for a recreational purpose. Next, she was able to identify four different software titles from a list of thirteen, which indicates that she is aware of only a few different programs. Finally, she has used some computer programs for educational activities. Over the duration of the study, this participant had difficulties logging onto the college system and navigating different programs.

Participant female two identified on the CEQ that she has not engaged in video gaming or social networking. This indicates that she does not use the computer for a recreational purpose. Next, she was able to identify one software title from a list of thirteen, which indicates that she is not aware of different computer programs. Finally, she has used some computer programs for educational activities. Over the duration of the study, this participant had some difficulties logging onto the system but was very determined to learn new and different programs.

Participant, male one identified on the CEQ that he does engaged in video gaming or social networking. This indicates that he does use a computer for a recreational purpose. Next, he was able to identify three different software titles from a list of thirteen, which indicates that he is aware of a few different programs. Finally, he has used some computer programs for educational activities. Over the duration of the study, this participant had no difficulties logging onto the system and navigating different programs. He supported other participants and was eager to learn new programs.

Participant, male two identified on the CEQ that he has not engaged in video gaming or social networking. This indicates that he does not use the computer for a recreational purpose. Next, he was able to identify two different software titles from a list of thirteen, which indicates that he is aware of only a few different programs. Finally, he has used some computer programs for educational activities. Over the duration of the study, this participant had no difficulties logging onto the system but did become frustrated navigating different programs.

Based on the participants' indicated time spent using social networks or video games (not at all or 13 hours), it can be concluded that ESL adult students do not engage in gaming often. The participants in this study were generally not able to identify different software, which extends the first observations that ESL adult students do not often engage in activities using technology. Many different variables such as time, access, training, or interest contribute to the reported low findings. Participants in this study identified a mean of $26.5 \%$ out of the possible thirteen possible different educational activities. The only activities that all of the participants have engaged in prior to this study were using a library database to locate online journals. All of the other activities may not have been taught based on their prior educational experience.

The CEQ provided a glimpse into the computer experiences that participants were bringing to this research study and to their program. It is imperative to identify the limited use, time, knowledge, and educational activities that participants have prior exposure to entering post secondary. Understanding a student's prior computer experience will also prevent participants from becoming overwhelmed and abandoning the new technology that could assist their individual lexical development.

\subsection{AT Post Vocabulary Questionnaire}

The AT post vocabulary questionnaire specifically asked participants about their individual use of the R\&WG program as well as their individual use of the different features. Participants were first asked to identify which R\&WG features they used from a list of seven and if they found the R\&WG program useful. This provided data specifically about the AT taught to support the lexical development of the participants.

Overall, the participants used 32\% out of seven different R\&WG features that were available to them through the AT (see table 2). Three out of four of the participants identified that they used the features because it was; "time saving," "understand," and "learn more."

Table 2.Participant Identified R\&WG Feature

\begin{tabular}{|c|c|c|}
\hline Participant & $\begin{array}{l}\text { Percentage of Yes } \\
\text { Features }\end{array}$ & No \\
\hline Female 1 & $29 \%$ & $\mathrm{X}$ \\
\hline
\end{tabular}




\begin{tabular}{llll} 
Female 2 & $43 \%$ & $\mathrm{X}$ & \\
Male 1 & $14 \%$ & $\mathrm{X}$ & \\
Male 2 & $43 \%$ & $\mathrm{X}$ & \\
\hline Percentage & $32 \%$ & $75 \%$ & $25 \%$ \\
\hline
\end{tabular}

Specifically, there are seven different features that were taught to the participants: text-to-speech, speaking dictionary, word prediction, pronunciation tutor, homonyms, spelling, and fact finder. The textto-speech function can read any digital document and most web pages. The participant needs to highlight an area of text and press play to start the feature which also visually highlights the words as the program read. The spelling dictionary opens an extra window that has different word meanings which can all be read aloud. Word predication is used for writing and when the feature is open a little box will predict possible words that start with the letters that are being typed. The homonym function permits students to ensure they are using the correct spelling of a word that is a homonym. The spell check builds upon the document's built-in spell check by providing instant access to the speaking dictionary. Finally, the fact finder is linked to Google and accesses websites that are formatted for a screen reader [19]. All, of the participants have indicated using the TTS feature and the speaking dictionary was the second most common feature reported (see table 3).

Table 3. Individual Participant Identification of R\&WG Features

\begin{tabular}{cccccccc}
\hline Participant & TTS & $\begin{array}{c}\text { Speaking } \\
\text { Dictionary }\end{array}$ & $\begin{array}{c}\text { Word } \\
\text { Predication }\end{array}$ & $\begin{array}{c}\text { Pronunciation } \\
\text { Tutor }\end{array}$ & $\begin{array}{c}\text { Homophone } \\
\text { Support }\end{array}$ & $\begin{array}{c}\text { Spelling } \\
\text { Support }\end{array}$ & $\begin{array}{c}\text { Fact } \\
\text { Finder }\end{array}$ \\
\hline Female 1 & $\mathrm{X}$ & $\mathrm{X}$ & & $\mathrm{X}$ & & & \\
Female 2 & $\mathrm{X}$ & & & $\mathrm{X}$ & & & \\
Male 1 & $\mathrm{X}$ & $\mathrm{X}$ & $\mathrm{X}$ & & & & \\
Male 2 & $\mathrm{X}$ & $\mathrm{X}$ & & & & 1 & 0 \\
\hline Frequency & 4 & 2 & 1 & 1 & 0 & 1 \\
\hline
\end{tabular}

Participants then were asked to list ten new vocabulary words they learned over the semester without any strategy support but to indicate if they learned the meaning of the word in class, by using technology or both.

Overall, participants were able to list on average $77.5 \%$, of the ten words, which is almost eight new health care vocabulary words that they have learned over the semester. On average, the participants reported that they learned $20 \%$ of the words in class, $24 \%$ of the words using both technology and class materials and finally $56 \%$ of the words listed were learned using technology (see table 4).

Table 4. Vocabulary Words Learned Over the Study and Location

\begin{tabular}{ccccc}
\hline Participant Percentage Class & R\&WG & Both \\
Listed & & & \\
\hline Female 1 & $60 \%$ & $83 \%$ & & $17 \%$ \\
Female 2 & $70 \%$ & & $71 \%$ & $29 \%$ \\
Male 1 & $100 \%$ & & $100 \%$ & \\
Male 2 & $80 \%$ & & $50 \%$ & $50 \%$ \\
\hline Mean & $77.5 \%$ & $20 \%$ & $56 \%$ & $24 \%$ \\
\hline
\end{tabular}

All four participants in this study used at least one to four different features from the R\&WG program for assistance in their English course. Some of the other features indicated by the participants were the internet, other students in the class, the instructor and essay writing workshops. On the open ended questions students wrote comments that the technology assisted them in: 'improvement from the beginning of term' and 'learned new vocabulary.' 'It helped me understand computer literature,' 'It taught me different reading strategies,' 'Improved learning and computer skills,' and 'I learned a lot from the session.' Finally, at the end of the questionnaire, participants were asked to identify what was most and least beneficial about the sessions. Some of the written comments were that the most beneficial elements of the sessions were: 'review time,' 'the teacher,' 'using the R\&WG system' and 'all.' These comments illustrate that each participant found a different aspect beneficial but all of the participants did learn something new. One negative response to this question which was echoed by other respondents was that the time for these support sessions were limited due to other obligations.

\subsection{Study Session Evaluation (SSE).}

The SSE was comprised of open-ended questions for participants to provide feedback about the different strategy sessions that they attend over the semester. The first question asked how often the participant attended strategy sessions.

All of the participants indicated that they often or always attended strategy session which proves that students found the session useful (see Table 5). 
Table 5. Individual Participations Reflection on Session Attendance

\begin{tabular}{|c|c|c|c|}
\hline Participant & Never & Often & Always \\
\hline Female 1 & & & $x$ \\
\hline Female 2 & & & $x$ \\
\hline Male 1 & & $x$ & \\
\hline Male 2 & & $x$ & \\
\hline Percentage & & $50 \%$ & $50 \%$ \\
\hline
\end{tabular}

The next question asked students if the objectives were met as outlined by the researcher at the start of the session.

Table 6. Individual Participants Report on Objectives Met During Sessions Participant No Partially Fully Comments

\begin{tabular}{|c|c|c|}
\hline Female 1 & $X$ & \\
\hline Female 2 & X & \\
\hline Male 1 & & $\begin{array}{r}\text { X I learned new } \\
\text { things }\end{array}$ \\
\hline Male 2 & X & $\begin{array}{r}\text { Limited time } \\
\text { at end }\end{array}$ \\
\hline
\end{tabular}

Overall, most of the participants identified that they felt that the objectives of learning the technological strategies were partially met (see table 6). Two participants wrote in, "I learned new things," and "limited time at the end." These comments suggest that the objectives of learning VLS using technology were met except there was not enough time to master the skills.

The next question asked participants specifically if they learned new strategies and if the new strategies assisted them in acquiring lexical knowledge (see Table 7).

Table 7. Individual Participants Identification of Strategy Use as well as Strategy Benefit Participant Excellent Good Poor Fair

\begin{tabular}{lll}
\hline Female 1 & $\mathrm{X}$ & $\mathrm{X}$ \\
Female 2 & \\
Male 1 & $\mathrm{X}$ \\
\hline
\end{tabular}

\begin{tabular}{lll}
\hline Male 2 & $\mathrm{X}$ \\
\hline Percentage & $75 \%$ & $25 \%$ \\
\hline
\end{tabular}

All participants identified that they learned new strategies over the duration of the session. They also identified that the strategies that they have learned assisted them in acquiring lexical knowledge. Two participants wrote in that they, "improved from beginning of term," and "learned new vocabulary." Overall, it can be concluded that the strategies that the participants learned were beneficial and useful for their lexical acquisition.

Now, participants were asked to rate their overall experience in the sessions. This would include the time, presenter, materials shared, technologies and strategies (see Table 8).

\section{Table 8. Individual Participants Rating of the Overall Sessions}

\begin{tabular}{lccc}
\hline Participant & Excellent & Good & Poor Fair \\
\hline Female 1 & & $\mathrm{X}$ & \\
Female 2 & & $\mathrm{X}$ & \\
Male 1 & $\mathrm{X}$ & \\
Male 2 & $\mathrm{X}$ & \\
\hline Percentage & $50 \%$ & $50 \%$ \\
\hline
\end{tabular}

The participants were evenly distributed between rating the sessions as excellent and good. It can be concluded that participants did find the sessions beneficial and they enjoyed attending.

The next questions participants were asked was how valuable they found the session.

All of the participants agreed that the sessions were valuable with each participant writing in a comment. The first participant wrote, "It helped me understand computer literature.” It can be concluded that this participant gained technological awareness from the sessions. The next participant noted that, "it taught me different reading strategies." This participant gained more strategies to assist in reading English and medical journals. The next participant wrote that he, "improved learning and computer skills." This participant learned different strategies that increased his learning strategies and technology strategies. Finally the last participant wrote, "I learned alot from the session." This participant did not directly identify what strategies or technologies were beneficial but it can be concluded that the participant gained strategic knowledge on how to be a good learner (see Table 9). 
Table 9. Individual Participants Identification of Sessions Value

\begin{tabular}{lll}
\hline Participant & Yes & No Comment \\
\hline Female 1 & $\mathrm{X}$ & $\begin{array}{l}\text { It helped me } \\
\text { understand computer } \\
\text { literature. } \\
\text { It taught me different } \\
\text { reading strategies }\end{array}$ \\
Memale 2 & $\mathrm{X}$ & $\begin{array}{l}\text { Improved learning and } \\
\text { computer skills } \\
\text { I learned a lot from } \\
\text { Session }\end{array}$ \\
Male 2 & $\mathrm{X}$ &
\end{tabular}

The last question asked participants to identify what was most and least beneficial about the sessions over the duration of the semester.

All of the participants noted beneficial aspects of the sessions as providing, "review time," "the teacher," "using R\&WG," and "all." One of the participants noted the least beneficial aspect of the session was the "limited time" (see table 10).

Table 10. Individual Participants Reported Beneficial Aspects of Sessions Participant Most Least

\begin{tabular}{lll}
\hline Female 1 & Review Time & \\
Female 2 & The Teacher $\quad$ Limited Time
\end{tabular}

Male 1 Using RW\&G system

Male 2 All

The data from this study had participants provide feedback at the beginning of the session as well as at the end. Separating the data collection provided the opportunity for the researcher to observe the changes in vocabulary strategy use over one semester. Participants identified their prior computer skills and knowledge in the CEQ. It is import to note that participants did not have extensive computer background knowledge or educational technology experience. Out of the four participants, three identified that they used the R\&WG program to support their lexical knowledge but all have identify trying TTS as a strategy. Reported in this research, participants in this study stated, that they all learned new strategies and strategies assisted them in their individual vocabulary development. One of the participants noted an improvement in her vocabulary from the beginning of term to the end, while another participant responded that the strategies assisted him in learning new vocabularyFinally, participants were asked to provide feedback about the overall experience they had during the session. It is encouraging to report that overall the participants enjoyed the sessions and found the technology strategies useful in learning new vocabulary.

\section{Conclusion}

Assistive technologies have been researched in the area of special education to assist struggling students as well as students with special needs. "We seek to capture the potential of technology for supporting the performance of struggling readers, such bias must be overcome in the quest to provide struggling students with appropriate tools to enhance their performance, learning, and achievement," [24] (p. 151). AT can assist student development by matching tools with the student's needs. TTS has been identified as a supportive tool for ESL and struggling readers. Educational technologies such as TTS may create authentic, supportive activities that teachers strive to provide [18]. Research has demonstrated the benefit of hearing the new language to support the acquisition of a second language. TTS software can provide individual control over repetition of words, phrases and passages [12]. Assistive technologies can embody the principle of Universal Design for Learning (UDL) in supporting all students in the general classroom environment while scaffolding their individual needs.

"The AT perspective seeks solutions that take into account a student's strengths and weaknesses, which are then used to create an independent technology-enhanced plan for the student to overcome his or her limitations. The UDL perspective looks to create flexible instruction, engagement, and assessment options that reduce barriers at the outset of the learning process," [16] (p. 9).

The application of UDL to the educational environment along with AT's provides students access to building on their strengths to compensate for their weaknesses. Although historically ATs have only been used by students with disabilities, applying UDL has expanded the use of ATs to a greater variety of students. Since ATs in a UDL environment can support all individual students, students who are struggling, in particular ESL students have benefited from constant access to this support. The importance of basic language skills has been noted in reading and language programs [6]. When adult students continue to struggle even in post-secondary programs, it has been noted that many have not received the individualized support necessary to master reading in their earlier reading experiences [6]. Engstrom [8] applied AT as a quick 
access strategic supportive tool for the students to increase their learning. It was suggested by Engstrom [8] that to support language development, the AT tool needs to be matched with the strategic support the student needs.

This study and the accompanying review of research suggest that ATs do assist adult ESL vocabulary development. As well, R\&WG is one program of many that could increase individual vocabulary knowledge through flexible scaffold supports.

\subsection{Implications for Practice}

Post secondary institutions, specifically community colleges, are facing an increase in enrollment of ESL learners. As this will increase the diversity in the classroom, educational, community institutions will need to respond to the unique challenges that the new student population will produce or create. Changing student populations result in modifications to how faculty instructors are delivering their courses. As this research has identified, teaching students strategic learning skills may be a transferable and useful skill as students pursue academic autonomy. The following section will outline possible considerations that will promote strategic learning.

The first consideration needs to apply to the classroom as well as the entire post-secondary environment. UD has been identified in research as well as in this study as strategic support for all students. A principle of UD is that educators proactively shape the environment to accommodate individual differences. By designing proactively, a wide variety of individual difference and preferences will be addressed and all students will have equal access. Specifically, in this study UD was only possible in the strategy session conducted by the researcher. This was extended by the current agreement for a site license for the R\&WG program to be accessible on all of the computers on campus. One of the questions that the participants did ask during the study was if they could have access to the program at home. This limitation decreased the accessibility and use of the RW\&G program for the participants at all times, an important principle of UD. Slowly changing the environmental structure will better meet the needs of the new diverse population. These principles support all students in the classroom regardless of their individual needs [20]. Administration needs to work with faculty to provide more students, not just ESL learners, and the benefits of the UD environment.

Secondly, faculty needs the opportunity to become more involved in integration of technological strategies through professional development. Research has indicated that faculty instructors are feeling overwhelmed with technological expectations, the diverse student population, and the expectation to apply best practices in the classroom [9]. All levels of post secondary education need to work together to provide time for collaboration and professional development. Input about best practices cannot be limited to the staff members only; therefore, students are starting to play a larger role in providing necessary feedback to improve teaching. In the pursuit of the scholarship of teaching, faculty are starting to share more ideas for incorporating technology, and best practices as strategic teaching. These changes are not drastic but do require support for faculty to learn and then apply different strategies into their daily lessons. It is imperative the positive experiences from this study can be continued by providing more choices for students to gain academic autonomy.

Finally, student support services need to be more integrated into all areas of the post secondary institution. With an increase of inclusion, student support services have the knowledge and experience to share with other faculty to support the diverse environment. This not only will provide support to students with special needs but also extend supports to struggling students and staff members. In many current post secondary structures student support services are a very small department that is mandated to only support students with special needs. As the post secondary educational environment changes towards online, the identified diverse population can benefit from using AT. Student support services could provide sessions for students and faculty to attend and learn more about accessibility of AT features. By increasing dialogue on AT strategies, student support services will be able to share other strategic learning skills with the entire institution. This working relationship will work both ways because faculty will gain more support by being able to discuss concerns and issues and student support services can be proactive in response to student needs.

These implications for practice are based on this study, which focused on student strategic choices. It is important that programs, which are student focused, ensure that their faculty is able to respond to student feedback. By creating a positive and collaborative environment, everyone involved will gain new strategies to learn and work more effectively.

\section{Acknowledgements}

We would like to express our profound gratitude to the students who participated in this study and give their time in this research. These participants provide insight into their learning journeys in language acquisition by sharing strategies and 
frustrations. Without their active participation this study would have not been possible.

\section{References}

[1] Boroch, D., Fillpot, J., Hope, L., \& Johnstone, R. (2007). Basic skills as a foundation for student success: A review of literature and effective practices. Journal of Applied Research in the Community College, 15(1), 81-86.

[2] Carey, S., \& Crittenden, E. (2000). Using technology to foster authentic communication for second language students. Paper presented at the Cross-Roads of the New Millennium. Proceedings of the Technological Education and National Development. Proceedings TEND Conference 2000, Abu Dhabi, April 8-10.

[3] Catts, H. W., Adolf, S.M., \& Weismer, S.E. (2006). Language deficits in poor comprehenders: A case for the simple view of reading. Journal of Speech, Language, and Hearing Research, 49(2), 278-293.

[4] Center for Canadian Language Benchmarks website. (2009). (Access date: 12 November 2010).

[5] Disseldorp, B., \& Chambers, D. (2002). Independent access: Which students might benefit from taking computers? In S. McNamara and E. Stacey (Eds), Untangling the Web: Establishing Learning Links. Proceedings ASET Conference 2002. Melbourne, 7-10 July.

[6] Durando, J. (2008). A Survey on literacy instruction for students with multiple disabilities. Journal of Visual Impairment \& Blindness, 102 (1), 40-46.

[7] Edyburn, D.L. (2007). Technology-enhanced reading performance: Defining a research agenda.

Reading Research Quarterly, 42(1), 146-158.

[8] Elkind, K. \& Elking, J. (2007). Text-to-speech software for reading. Perspectives on Language and Literacy, Summer, 11-16.

[9] Engstrom, E. U. (2005). Reading, writing, and assistive technology: An integrated developmental curriculum for college students. Journal of Adolescent \& Adult Literacy, 49(1), 30-39.

[10] Gallardo del Puerto, G., \& Gamboa, F. (2009). The evaluation of computer-mediated technology by second language teachers: Collaboration and interaction in CALL. Educational Media International, 42(2), 137-152.

[11]Gee, J.P. (2003). What Video Games Have to Teach us About Learning and Literacy. New York: Palgrave Macmillan.

[12] Kilickaya, F. (2006). 'Text-to-speech technology': What does it offer to foreign language learners? CALL-EJ Online, 7(2).

[13] Krach, K., (2007). Snapshot-ten years after the law: A survey of the current status of university web access. Journal of Special Education Technology, 22(4), 30-41.
[14]Lacina. J. (2004). Promoting language acquisitions: Technology and English language learners. Childhood Education, 81(2), 113-116.

[15] Lange, A. A., McPhillips, M., Mulhern, G., \& Whylie, J. (2006). Assistive software tools for secondary-level students with literacy difficulties. Journal of Special Education Technology, 21(3), 13-22.

[16] Martinez-Marrero, I., \& Estrada-Hernandez, N. (2008) Assistive technology: An instructional tool to assist college students with written language disabilities. TechTrends. 52(1), 56-63.

[17] NorQuest (2010). Innovative concepts compelling impacts. Applied Research Annual Review. (Access date: 9 August 2010).

[18] Phayer, J. (2010). The road to success: How does the use of the test to speech application, read and write gold, help college students with dyslexia? Special Education Technology Practice, January/February, 22-29.

[19] Roberts, G., Torgesen, J., Boardman, A., \& Scammacca, N. (2008). Evidence-based strategies for reading instruction of older students with learning disabilities. The Division for Learning Disabilities of the Council for Exceptional Children, 23(2), 63-39.

[20] Rose, D, H., Hasselbring, T, S., Stahi, S., \& Zabala, J. (2005). Assistive technology and universal design for learning: Two sides of the same coin. In Edyburn, D., Higgins, K., \& Boone, R. (Eds.) Handbook of Special Education Research and Practice (pp 507- 518). Whitefish Bay: Knowledge by Design, Inc.

[21] Silver-Pacuilla, H. (2006) Access and benefits: Assistive technology in adult literacy. Journal of Adolescent \& Adult Literacy, 50(2), 114-125.

[22] Sorrell, C. A., Bell, S.M., \& McCallum, R.S. (2007). Reading rate and comprehension as a function of computerized versus traditional presentation mode: A preliminary study. Journal of Special Education Technology, 22(1), 1-12.

[23] Swanson, H. L. (1999). Reading research for students with LD: A meta-analysis of intervention outcomes. Journal of Learning Disabilities, 32, 504-532.

[24] textHELP (2010). Read and Write Gold (Version 8.0) [Computer Software], Antrim: textHELP Systems. (Access date: 5 November 2010).

[25] Wald, M., Draffan, E, A. \& Seale, J. (2009). Disabled learners' experiences of E-learning. Journal of Educational Multimedia and Hypermedia, 18(3), 341-362. 